\title{
THERMOGRAVIMETRIC AND KINETIC STUDY OF METHYLOLMELAMINE PHOSPHATE TREATED - COTTON FABRIC
}

\author{
Ayeni, N.A., Adeniyi, A., Abdullahi, N.N., Bernard, E. and Ogunleye, A.O.
}

1Department of Chemistry, Federal College of Education, Kano - Nigeria

2Department of Chemistry, Federal College of Education (Technical), Bichi, Kano - Nigeria

*Correspondence author: nurudeenayeni@yahoo.com

\begin{abstract}
Some salient properties of cotton cellulose which requires it to be treated with additives to improve its versatility were examined taken into consideration, the molecular structure. Thermogravimetric analysis of the cotton fabric and the treated cotton fabric were carried out in an improvised muffled furnace. The result was in accordance with the previous study carried out on cellulose showing two stages of thermal degradation with first degradation between $250^{\circ} \mathrm{C}-300^{\circ} \mathrm{C}$ and estimated $75 \%$ weight loss. The treated fabrics show degradation at $200^{\circ} \mathrm{C}-250^{\circ} \mathrm{C}$ with an estimated $10 \%-25 \%$ weight loss and more stages of thermal degradation. This may be attributed to the structural modification of the cotton cellulose upon resination with methylolmelamine phosphate.

Keywords: Cotton Fabric, Degradation, Resination, Thermogravimetric
\end{abstract}

\section{INTRODUCTION}

Cotton fabrics generally possess some salient properties that warrant their treatment for better applicability. They are naturally susceptible to creasing during processing and in use, hence the need to improve their resistance to creasing. Cotton is highly hydrophobic with higher potential to absorb water more than 27 times its weight (www.ehow.com). The fabric was ranked among the fabrics that propagate fire with ease generating toxic gases upon ignition at a temperature above $300^{\circ} \mathrm{C}$ (Muller and Couchard, 1976). These properties mentioned so far can be better addressed if the major structure of the molecule that makes up the fabric is critically modified. Raw cotton, by analysis composes of mainly cellulose $(80-90 \%)$ with water, waxes, fat, protein, hemicelluloses, pectin, coloring matter and ash making up the rest component in specific quantities (Duckett, 1975). During purification by scouring or mercerization (treatment of the fiber with caustic soda or aqueous ammonia), natural waxes and fats in the fiber are saponified and pectin's and other noncellulose materials are released, so that the impurities can be removed by just rinsing away. After scouring, a bleaching solution (consisting of a stabilized oxidizing agent) interacts with the fiber and the natural color is removed. Bleaching takes place at elevated temperature for a fixed period of time. These processes rendered the cotton $99 \%$ cellulose in nature.

Cellulose is essentially condensation polymer of $\beta$-D- glucopyranose with 1,4-glycosidic linkages. The polymeric chains are held together by extensive hydrogen bonding between hydroxyl groups. The large number of this hydroxyl groups readily form hydrogen bonds with water and are therefore responsible for the fiber's hydrophilic nature. Owning to degradation during processing, a $\mathrm{C}_{(6)}$ primary hydroxyl group on $-\mathrm{CH}_{2} \mathrm{OH}$ is replaced by a carboxyl group $(-\mathrm{COOH})$ periodically along the chain. Under alkaline condition, ionization of the hydroxyl groups confers a higher negative charge on the fiber and in addition, breaks down the intermolecular hydrogen bonding thus causing charge repulsion between the polymer chains and swelling with attendant decrease in the degree of polymerization as observed by Hamilton and Mitchell (1975). The presence of these hydroxyl groups also provides points of weak Van der Waals forces and hydrogen bonding between the chains that are primarily responsible for creasing coupled with presence of amorphous region in the structure (Nkeonye, 1990).

Apart from the weak bonding between the molecules, elemental compositions of cellulose mostly the hydrogen and oxygen makes it less resistance to heat and flaming (Gauthier et al.,1981), even though there is a notion that the weave pattern of the fabric also affects the flame retardancy (Horrocks, 1986). In the event of decomposition of cellulose fiber occasioned by heat or flaming as observed by Mok and Antal (1983), the pathway include both exothermic via anhydrocellulose formation and endothermic via levoglucosan formation which was observed to be the main volatile fuel forming pyrolysis reaction which propagates fire. The endothermic devolatilization process that can lead to predominantly tarry vapor is of practical importance. The mechanism of propagation of fire by cellulose proposed by Horrocks (1986) pointed out that the polymer first pyrolyzed at decomposition point into hydrogen and carbon monoxide and the subsequent reaction of these pyrolysis gases with the sufficient oxygen lead to a higher exothermic reaction that propagated fire. Previous investigations (Ajayi et al., 2001 and Ayeni, 2011) have shown that cellulose structure could be stabilized by the introduction of low molecular weight pre-condensate like methylol urea and methylol melamine. The polymerization of these precondensates upon drying and curing at elevated temperature, supplements the weak hydrogen and Van der Waals forces as well strengthen the amorphous regions of cellulose. 
Also the stabilization of cellulose structure to resist heat and flaming through introduction of various types of flame retardant additives has been investigated (www.special4polymers.com). The suitability of these flame retardant additives is driven by their cost of production, safe handing, toxicity, low smoke density and environmental friendliness. Organophosphorus base flame retardants containing active nitrogen have been particularly used on cellulose textiles. The nitrogen acts as a nucleophile with respect to the phosphorus entity thereby creating polymeric species having Phosphorus - Nitrogen polar bonds. The enhanced electrophilicity of the phosphorus increases its ability to phosphorylate the $\mathrm{C}_{(6)}$ primary hydroxyl group on each $\left(-\mathrm{CH}_{2} \mathrm{OH}\right)$ anhydroglucopyranose repeat unit within the cellulose molecule. This prevents the intramolecular $C_{(6)}-C_{(1)}$ laevoglucosan-forming reaction to occur which is the main volatile fuel forming pyrolysis reaction (Abella et al., 2007). The effect of using THPC as a finishing agent on cotton fiber in particular increases the flame retardancy but surprisingly decreases its pyrolysis temperature from $350^{\circ} \mathrm{C}$ to $307^{\circ} \mathrm{C}$ (Tai and Needles, 1979). In self-charring materials such as cellulose, melamine phosphate has been used as intumescences combining both the melamine and catalyst functionality. The weight losses of the fabric as a function of heat applied have been successfully used to measure the heat resistance which is the major basis of thermogravimetric analysis (TGA). The technique has been used primarily to predict the thermal stability of fabrics at temperatures up to $1000^{\circ} \mathrm{C}$ as well as kinetic approach to predict polymer's life time under specific test conditions. Since thermal stability, crease resistance and hydrophilicity are all function of the fiber structure, any changes in the cellulose structure is likely to alter these properties. The aim of this paper is to verify the thermal stability and kinetic of a modified cellulose structure using cotton fabric treated with methylolmelamine phosphate.

\section{MATERIALS AND METHODS Fabric treatment}

A plain woven $100 \%$ cotton fabric (CF) was used. The fabric was cut to $10 \mathrm{~cm} \times 10 \mathrm{~cm}$ dimension and purified by process of scouring (Ajayi et al., 2001). This involved treating the fabrics in $10 \%$ aqueous ammonia using liquor ratio (L.R $1: 50$ ) at $5^{\circ} \mathrm{C}$ for 30 min., neutralized in $1 \%$ acetic acid, rinsed with water and dried for 24hrs. Methylolmelamine phosphate of different degree of methylol substitution, prepared and characterized were used (Ayeni 2011). These includes monomethylolmelamine phosphate $\left(M P R_{1}\right)$, dimethylolmelamine phosphate $\left(\mathrm{MPR}_{2}\right)$, trimethylolmelamine phosphate $\left(\mathrm{MPR}_{3}\right)$, tetramethylolmelamine phosphate $\left(\mathrm{MPR}_{4}\right)$, Application of the resins involves treating the fabrics by impregnation with each of the samples. The fabrics were then cured in oven at $100^{\circ} \mathrm{C}$ for 15 minutes.

\section{Thermogravimetric analysis}

Thermal oxidative degradation of the pure cotton fabric and the treated fabrics samples was carried out in an improvised instrument as against the conventional thermogravimetric instruments. Here a Gallenkamp muffle furnace having heating capacity of $50^{\circ} \mathrm{C}$ to $1000^{\circ} \mathrm{C}$ was used. $1 \mathrm{~g}$ each of the fabric sample was placed separately in a platinum crucible and both weighed before being transferred into the furnace. The samples were analyzed at ambient temperature to $600^{\circ} \mathrm{C}$ at heating rate of $50^{\circ} \mathrm{C} / \mathrm{min}$. The sample's weights were immediately taken and transferred back into the furnace for further heating after every $50^{\circ} \mathrm{C}$ rise in temperature over a period of 1minute.

\section{RESULTS AND DISCUSSION}

Thermogravimetric (TG) curves of cotton fabric (CF) and its resinated samples (CF-MPR series) were obtained by plotting the weight loss of samples at every $50^{\circ} \mathrm{C} / \mathrm{min}$ rise in temperature. TG curve of CF shows two stages of thermal degradation. First stage occurs between $250^{\circ} \mathrm{C}-300^{\circ} \mathrm{C}$ with mass loss of about $75 \%$. The observed decrease in the weight may be attributed to dehydration of the cotton cellulose and oxidative thermal degradation, where large amount of flammable volatile compound are formed (Kaur et.al., 1986). The TG curves for CF-MPR series show more stages of thermal degradation compared to CF. The reason behind this resistance to heat may be due to increase in the degree of crosslinking as the methylol group in the resin increases. This is because crosslinking of the resins in the cotton fabrics promotes the stabilization of the structure of cellulose by providing additional, covalent bonds between the chains, which are stronger than the conventional hydrogen bonds, and which have to be broken before the stepwise degradation of the chain occurs on heating (Grand and wilkie, 2000). The first stage of thermal degradation of CF-MPR series occur between $200^{\circ} \mathrm{C}$ and $250^{\circ} \mathrm{C}$ which tallies with temperature range at which melamine phosphate melts. Therefore the decomposition of melamine phosphate in the CFMPR series may have lead to their earlier degradation at a temperature below that of CF producing char with the molten polymer thus preventing drastic decrease in mass of the treated fabric as heating progresses.

$$
\mathrm{CF}_{-M P R_{4}} \text {, CF-MPR }{ }_{3} \text { CF-MPR }{ }_{2} \text { CF-MPR }
$$
recorded a percentage mass loss of $10,15,19,25 \%$ respectively (Table 1 ). CF-MPR series may have shown more resistance to flaming because phosphorus containing flame retardants alter the course of decomposition of the cellulosic material so that lower amount of flammable volatiles and large quantities of intumesce char are formed (Saxena et al,.1992). Intumesces char formed do hinders the passage of the combustible gases and molten polymer as well as shield the polymer from heat (Le Bras et al., 1998). Also, an improved resistance to heat as the methylol group increases in the CF-MPR series may also be attributed to crosslinking of the resin in the fabric as it was recognized that crosslinking equally promotes char formation in pyrolysis of celluloses (Grand and Wilkie, 2000). 
Table 1: First Stage Thermal Degradation of cotton (CF) and resinated cotton (CF-MPR)

\begin{tabular}{lcccc}
\hline Samples & Degradation at First Stage & $\begin{array}{c}\text { Temperature Range } \\
\left({ }^{\mathbf{0}} \mathbf{C}\right)\end{array}$ & $\begin{array}{c}\text { Mass Loss } \\
(\mathbf{\%})\end{array}$ & $\begin{array}{c}\text { Activation Energy } \\
(\mathbf{K j} / \mathbf{m o l} \mathbf{)})\end{array}$ \\
\hline $\mathrm{CF}$ & $0.85-0.2125$ & $250-300$ & 75 & 172.84 \\
$\mathrm{CF}-\mathrm{MPR}_{1}$ & $0.85-0.6375$ & $200-250$ & 25 & 159.55 \\
$\mathrm{CF}_{\mathrm{MPR}}$ & $0.85-0.6885$ & $200-250$ & 19 & 140.44 \\
$\mathrm{CF}_{2} \mathrm{MPR}_{3}$ & $0.85-0.7225$ & $200-250$ & 15 & 131.30 \\
$\mathrm{CF}_{-} \mathrm{MPR}_{4}$ & $0.85-0.7680$ & $200-250$ & 10 & 127.14 \\
\hline
\end{tabular}

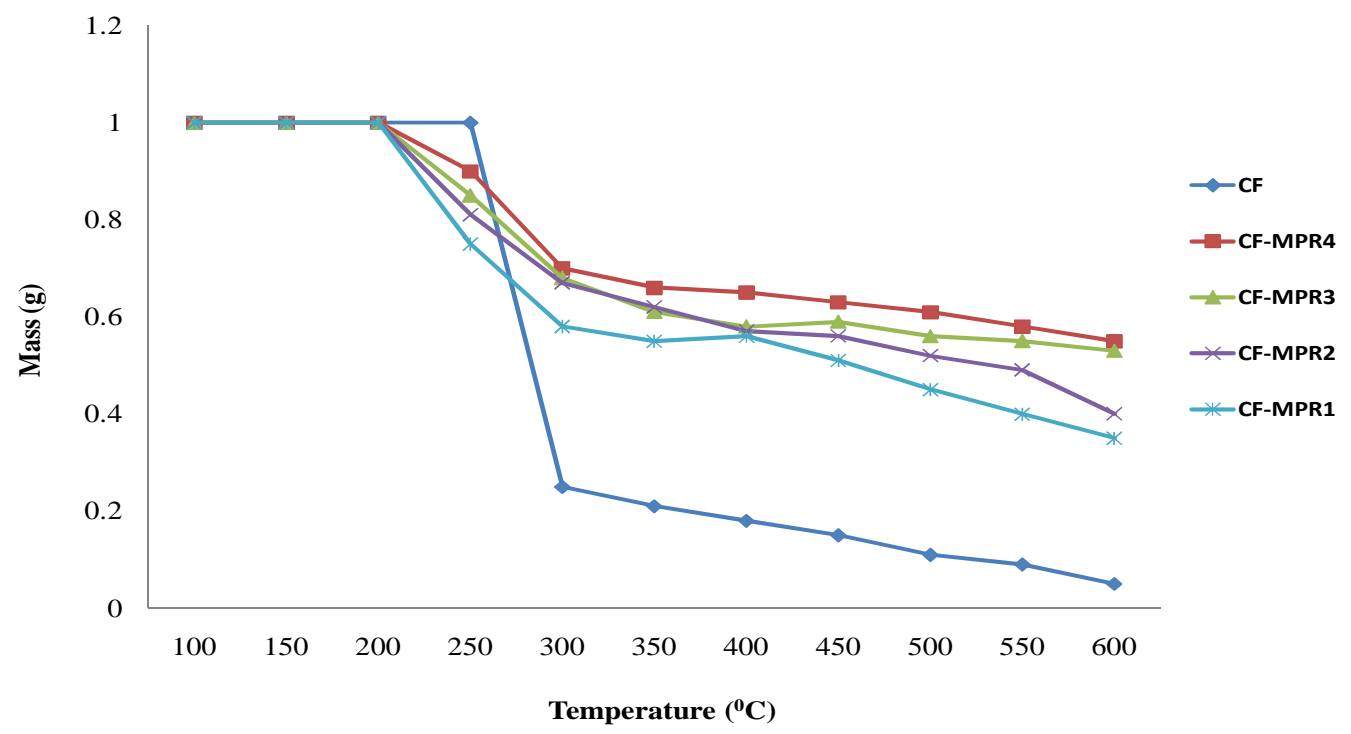

Figure 1: TG curves at heating rate $50^{\circ} \mathrm{C} / \mathrm{min}$ of CF-MPR series using $15 \%$ resin, cured at $100^{\circ} \mathrm{C}$ for $15 \mathrm{~min}$

The possibilities of the stability of the fabric brought about by the resination with CF-MPR series may be viewed from two different perspectives. It is possible that the cellulose is phosphorylated by nucleophilic addition of cellulosate ion to the phosphonium ion before crosslinking takes place when cured as presented in scheme 1.

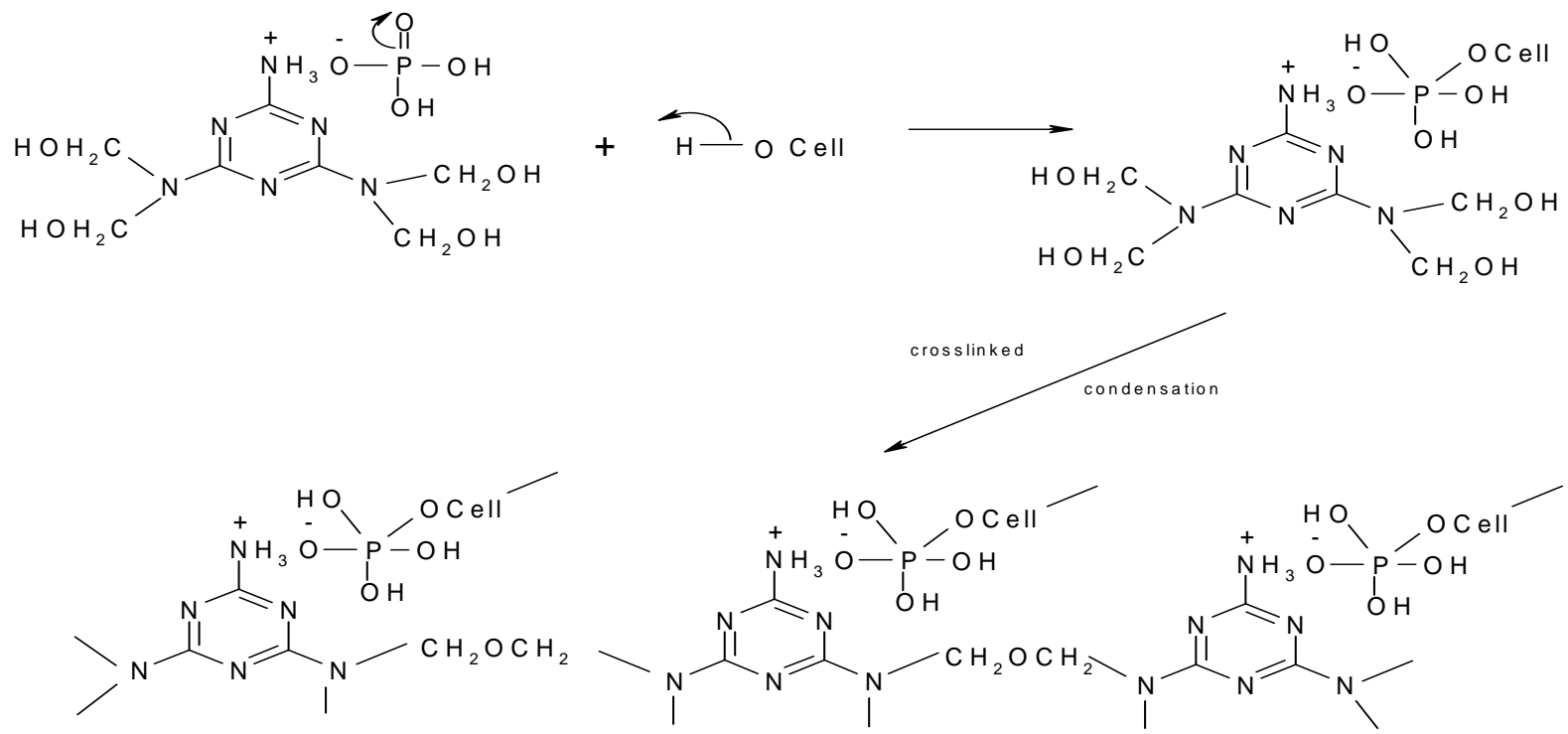

Scheme 1: Resination and crosslinking of $\mathrm{MPR}_{4}$ in cellulose (first possibility) 
On the other hand, it could be that the methylol group of the resin condensed with the cellulose fabric before crosslinking takes place when cured.<smiles>O=[N+]([O-])[N+](=O)[O-]</smiles><smiles>C[CH]OCOC(C)CN(C)c1nc([NH3+])nc(N(C)C)n1</smiles>

Scheme 2: Resination and crosslinking of $\mathrm{MPR}_{4}$ in cellulose (second possibility)

However the attachment of the cellulose to the resin via the phosphate end is more favored considering higher affinity the phosphorus ion will have for the cellulosate ion compared to the carbonium ion.

\section{Kinetic Study}

The thermogravimetry (TG) data were analyzed for kinetic study (Dahiya and Kumar, 2009). Here is it assumed that only a single reaction occur while a sample of the resinated fabric undergoes a certain temperature rise at a steady heating rate of $50^{\circ} \mathrm{C} / \mathrm{min}$. Thus mass change against temperature can be described as

$$
\frac{d \alpha}{d T}=\frac{A}{\beta} e^{E / R T}(1-\alpha)^{n}
$$

Equation 1

Where

$$
\begin{aligned}
& n=\text { reaction order } \\
& A=\text { pre-exponential factor } \\
& E=\text { Activation Energy } \\
& \beta=\text { heating rate } \\
& T=\text { Temperature in }(K)
\end{aligned}
$$

$\alpha=$ non dimensional change in mass given as $\left(m_{o}-m\right) /\left(m_{o}-m_{f}\right)$

$$
\begin{aligned}
& m_{o}=\text { initial mass of sample before treatment } \\
& m=\text { sample mass at temperature ' } \mathrm{T}^{\prime} \\
& m_{f}=\text { final sample mass }
\end{aligned}
$$

$$
\int_{0}^{\epsilon} \frac{d \epsilon}{(1-\alpha)^{n}}=\frac{A}{\beta} \int_{T_{0}}^{T} e^{-\frac{\varepsilon}{K T}} d T
$$

Using approximation introduced by Coats - Redfern for $\mathrm{n} \quad=1$

$$
\ln \left[\frac{-\ln (1-a)}{T^{2}}\right]=\ln \left(\frac{A R}{\beta E}\right)+\ln \left(1-\frac{2 R T}{E}\right)-\frac{E}{R T} \quad \text { Equation } 2
$$

Where $A$ and $E$ are determined on TG data obtained experimentally at $50^{\circ} \mathrm{C} / \mathrm{min}$.

The activated energies from results obtained for the thermal degradation of CF and CF-MPR series were determined using first- order Coat-Redfern method on data obtained in the TG results. Activation Energies of all samples were calculated in common range of degree of conversion $(0.55-0.85)$ which fall in the first stage of thermal degradation as shown in Table 1.
Activation Energies of the entire resinated samples (CF-MPR series) were found to be lower than that of the CF. The observed decrease in activation energy may be attributed to the catalyzing effect of the phosphoric acid released when the methylolmelamine phosphate decomposed in the fabric, which suggest that dehydration path during thermal degradation of cotton is very much likely. 
Although the relatively large amount of the methylolmelamine phosphate used for the resination of the cotton fabric are not compatible with the definition of a catalyst. This suggests that the resins have an additional role of probably serving as an ingredient in the char formation at the expense of tarry vapor (Soares et al., 1995) and (Jimenez et al., 2006).

Again there is successive decrease in the activation energy as the methylol groups in the resins used increases. The degree of the crosslinking may also be a factor behind this trend because high degree of cross linking of resins in fabrics has been noted to increase thermal stability by decreasing the distance between the individual chains and consequently strengthening and fortifying the hydrogen bonds in

\section{REFERENCES}

Abella, L., Nanbu, S., and Fukuda, K. (2007). Theoretical Study on Levoglucosan Pyrolysis Reactions yielding Aldehydes and a Ketone in Biomass. Memoirs of Faculty of Engineering, Kyushu University,Vol.67, No. 2. Pp. $68-69$

Ajayi, J. Bello, K. and Boyede, F. (2001). Effect of Liquid Ammonia Pre-treatments on the Crease Recovery Properties of Resinated Cellulose Fabrics. J. Chem. Soc. Nig. 26 (1). $120-122$

Ayeni, N.A. (2011). Effect of Dye-Resin Complexation on Flame Retardant and Dyeing Properties Cellulosic Fiber Unpublished doctoral's thesis, ATBU, Bauchi

Carpentier, F., Le Bras, M.,G. Bourbigot, S. and Delobei, R. (2007). Polymer Processing, Fire Testing, Fire Retardancy of Polymeric Materials for Building, Electrical and Textile Application (Tech. Rep. BP 108, 59652. Villeneuve d'Asq, GePIFReM, ENSCL-C7, cite scientifique, Paris.

Dahiya, J.B. and Kumar, K. (2009). Flame Retardant Study of Cotton Coated with Intumescents: Kinetic and Effect of Metal Ion. Jour. of Scientific and Industrial Research. 68, 548 554.

Duckett, K.E.: "Surface Properties of Cotton Fibers", Surface Characteristics of Fibers and Textiles, edited by M.J.Schick. "Fiber Science Series", Marcel Dekker, Inc. 1975, p 67

Flame Retardant Additives. Retrieved from www.specialchem4polymers.com June, 2011

Gauthier, M. Deanin, R.D. and Pope, C.J. (1981). Manmade Fibres: Flame Retardance and Flame Retardants. Polymer-plastics Technology and Engineering (1) 16, 1 - 3

Grand, A.F. and Wilikie, C.A. (2000). Fire Retardancy of Polymeric Materials. In Grand and Wilkie (Eds). Mercel Dekker Pub. the cellulose (Carpentier et al., 1998) by implication this means a decrease in activation energy.

\section{CONCLUSION}

Upon application of the methylolmelamine phosphate to cotton fiber, a network of the resin - fiber was produced, the stability of which were established through improved resistance to heat. In the event of heat application, cotton fiber which is noted to be labile to heat and have high flame propagation record with evolution of toxic gases now become a flame retardant fiber with reduced fire risk and low smoke/toxic gas production when treated with the resins formed from methylolmelamine phosphate application. This translates reduced damage to expensive infrastructures which are cellulosic in nature with relatively less resistant to heat and flame.

Hamilton, J.K and Mitchell, R.L (1974) "Cellulose" Encylopedia of Chemical Technology $2^{\text {nd }}$ edn. 4, 593 - 616. Intersci. Publ., NY.

Horrocks, A.R. (1986). Flame Retardant Finishing of Textiles. A Review of Progress in Coloration and other Related Topics. 16, 62 - 95

Jimenez, M., Duquesne, S. and Bourbigot, S. (2006). Intumescent Fire Protecting Coating: Toward a better understanding of their mechanism of action. Thermochim Acta, 449, $16-26$

Kaur, B., Jain, R.K., Gur, I.S. and Bhatnagar, H.L. (1986). Thermal Stability of Phosphorylated Cellulose Modified with Various Transition Metal. Jour. Anal. Appl. Pyro. 9, 173 - 206

Le Bras, M. [Ed.] (1998). Fire Retardancy of Polymers: The used of Intumescences. Royal Society of Chem. Publishing

Mok, W.S.L and Antal, M.J (1983) Effect of Pressure on Biomass Pyrolysis: Heat of Reaction of Cellulose Pyrolysis. Thermochim Acta 68, 165

Muller, R and Couchard, P. (1976). Meliand Textilber. English Ed. Pp. 886.

Nkeonye, P.O. (1990). Fundamental Principle of Textile Dyeing Printing and Finishing. ABU Press Ltd., Zaria. Pp. $1-3$.

Properties of cotton fabric". Retrieved from: www.ehow.com/list 6389277 propertiescotton-fabric june, 2011

Saxena, N.K., Sharma, S.K. \& Gupta, D.R. (1992). Development and Evaluation of Fire Retardant Cotton Fabric. Jour.of Fire Science and Technology. 12 (2): $1-10$

Soares, S., Camino, G. \& Levchik, S. (1995). Comparative Study of the Thermal Decomposition of Pure Cellulose and Pulp Paper. Polym Degrad Stab. 49, 275 - 283.

Tai, A. and Needles, H.L. (1979), Flame Retardant Chemicals. Text. Research J. 49, 43 